NOTE

\title{
An outbreak of disease caused by Francisella sp. in Nile tilapia Oreochromis niloticus at a recirculation fish farm in the UK
}

\author{
Keith R. Jeffery*, David Stone, Stephen W. Feist, David W. Verner-Jeffreys \\ Centre for Environment, Fisheries and Aquaculture Science (Cefas), Barrack Road, Weymouth, Dorset DT4 8UB, UK
}

\begin{abstract}
This study details the first diagnosis of Francisella sp. in tilapia in the United Kingdom. Losses of tilapia fry at a recirculation fish farm in England were investigated, giving a presumptive positive diagnosis of infection with Francisella sp. by histopathological examination. Most fish sampled showed moderate to marked pathology of the major organs, with lesions being present in most tissues. The most obvious host response was granuloma formulation. A subsequent follow-up visit provided further evidence for the presence of a Francisella species. PCR amplicons were obtained using Francisella spp.-specific primers that shared $100 \%$ sequence identity with the 16S rRNA gene of the type strain of the species F. asiatica previously described as the cause of disease in tilapia in Southeast Asia and Central America. This outbreak and the subsequent investigation emphasise the importance of strict biosecurity at fish farms and the care that needs to be taken when using a new supplier of fish.
\end{abstract}

KEY WORDS: Francisellosis $\cdot$ Tilapia $\cdot$ Granulomas $\cdot$ Recirculation Resale or republication not permitted without written consent of the publisher

\section{INTRODUCTION}

The tilapia farming industry in England and Wales has seen a significant expansion in recent years. There are now at least 12 recirculation systems in operation, ranging in size from those producing just 5 tonnes of fish to those capable of producing several hundred tonnes of fish. Fully enclosed recirculation aquaculture has many advantages in terms of green credentials such as being able to farm close to markets, control of effluent and the elimination of predators, pests and escapees. It also gives control over the elements and allows optimal temperature control. Biosecurity and the introduction of pathogens are then under the control of the farm manager. However, this type of site has often experienced technical problems (Little et al. 2008). Tilapia have long been considered a species that is ideal for use in aquaculture due to its hardy nature, fast growth, tolerance of suboptimal water quality and disease resistance (Little et al. 2008). However, as with all species of farmed fish, tilapia are still affected by diseases, and vulnerability can increase with stock densities.

In SE Asia and Central America, for example, tilapia have been affected by a granulomatous disease caused by an intracellular bacterial pathogen (Chen et al. 1994). Studies have confirmed, using molecular techniques, that this is caused by a Francisella sp. (Hsieh et al. 2006, Mauel et al. 2007, Ottem et al. 2009, Mikalsen \& Colquhoun in press). Bacteria from the genus Francisella are characterised as strictly aerobic, facultatively intracellular, non-motile, Gram-negative cocco bacilli.

At least 2 closely related but distinguishable species of Francisella cause disease in fish. F. noatensis comb. nov., sp. nov. (Mikalsen \& Colquhoun in press) (syn = F. philomiragia subsp. noatensis [Mikalsen 2007] and F. piscicida [Ottem et al. 2007]), is the cause of disease in farmed and wild cod Gadus morhua in northern Europe (Ottem et al. 2009) and Atlantic salmon in Chile (Birkbeck et al. 2007). The second group, F. noatensis subsp. orientalis subsp. nov. (Ottem et al. 2009) (syn $=F$. asiatica sp. nov. [Mikalsen \& Colquhon 
in press]) is the cause of disease in farmed tilapia in Asia and South America (Hsieh et al. 2006, Mauel et al. 2007), three-lined grunt Parapristipoma trilineatum in Japan (Kamaishi et al. 2005) and a range of cichlid species (Hsieh et al. 2007).

\section{MATERIALS AND METHODS}

The UK Centre for Environment, Fisheries and Aquaculture Science (Cefas) Fish Health Inspectorate investigated a fish farm that was experiencing low level chronic losses of imported tilapia Oreochromis niloticus fry between 0.5 and $5 \mathrm{~g}$ in weight. Cumulative losses of fry were approximately $20 \%$ of each batch brought onto site. The fry were being ongrown between 24 to $27^{\circ} \mathrm{C}\left(23.9^{\circ} \mathrm{C}\right.$ at time of visit) and moved up through the system from shallow tanks into deeper tanks and then into suspended net hapas within raceways before they were ready for resale. The farm's primary function was ongrowing thousands of imported fry before supply to the main grow-out sites. The fry had been imported and sourced from several different sites over the year preceding the mortalities. There was no in-house fry production, although some future brood-fish were held. No other species of fish were held on site.

The site operated a recirculation system using large bead filters with a backwash system. Replacement water was supplied at approximately $2 \%$ per day. Water quality parameters recorded over the previous months were within acceptable ranges for this type of operation (e.g. total ammonia readings were $<1 \mathrm{mg} \mathrm{l}^{-1}$, nitrite was $<10 \mathrm{mg} \mathrm{l}^{-1}$ at a $\mathrm{pH}$ of 6.4). Oxygen levels were not documented, but flow rates and aeration in the tanks were observed to be high.

Sick and moribund fish were collected, and a range of samples were taken for the disease investigation. Pools of spleen, kidney and brain tissue ( $1 \mathrm{~g}$ total) from each of 5 fish were placed into viral transport medium, chilled and returned to the laboratory for standard cell culture techniques. Cell lines used included fathead minnow (FHM), chinook salmon embryo (CHSE), striped snakehead (SSN), blue gill fry caudal trunk (BF) and epithelial papilloma of carp (EPC); these were inoculated and incubated at both 20 and $25^{\circ} \mathrm{C}$.

Swabs were taken from kidney and spleen of sick fish and inoculated onto tryptone soya agar (TSA) and river Anacker Ordal modified agar (RIVAOA) plates. For the purposes of pathology and ultra-structural examination, tissues from kidney, spleen, gill, liver, intestine, heart, eye, skin and muscle were removed and fixed by placing in $10 \%$ neutral buffered formalin (NBF). Whole fish were also fixed. The samples were processed in paraffin wax using standard protocols. Sections were cut and mounted onto glass slides before staining with haematoxylin and eosin (H\&E). Sections were analysed by light microscopy (Eclipse E800, Nikon) and digital images were captured using the Lucia $^{\mathrm{TM}}$ Screen Measurement System (Nikon). Live fish were also selected and boxed and taken back to the Cefas laboratory for parasitological examination.

At a second visit, 7 wk later, the number of unhealthy fish in the system had declined. However, additional samples were taken from the remaining affected fish; swabs were taken from spleen, kidney and liver and inoculated onto cysteine heart agar (CHA) plates. Liver and spleen swabs were also taken onto Selective kidney disease media plates (SKDM). Further samples of heart, liver and spleen were again taken for histology and were fixed in NBF. In addition, 10 whole fry ( 0.5 g) that had recently been imported and stocked into a disinfected tank were preserved in NBF.

For molecular analyses, 10 samples (Sample nos. 11 to 20) of combined spleen liver and heart tissue, as well as whole newly imported fry, were taken and immediately stored in absolute ethanol until analysis. Tissues were removed from the ethanol, weighed and homogenised in transport medium using a Fastprep ${ }^{\mathrm{TM}}$ tissue disruptor (MP Biomedicals) to give $10 \% \mathrm{w} / \mathrm{v}$. Total nucleic acid was extracted from a $50 \mu \mathrm{l}$ aliquot of the homogenate using the Virus Mini Kit (Qiagen) and the EZ-1 BioRobot (Qiagen) eluting the nucleic acid in a volume of $60 \mu \mathrm{l}$.

Two separate PCR reactions were performed using Francisella-specific primers based on those of Barns et al. (2005). Mixed bases were introduced to increase the range of Francisella species that could be detected (Table 1).

PCR was performed in a $50 \mu \mathrm{l}$ reaction volume of $1 \times$ Go Taq PCR buffer containing $2.5 \mathrm{mM} \mathrm{MgCl}_{2}, 200 \mathrm{mM}$ dNTPs, $100 \mathrm{pmol}$ of the forward primer, $50 \mathrm{pmol}$ each of the reverse primers, 2.5 units of Go Taq DNA polymerase (Promega) and $2.5 \mu \mathrm{l}$ of the nucleic acid extract. The reaction mix was overlaid with mineral oil and subjected to 40 temperature cycles of $1 \mathrm{~min}$ at $95^{\circ} \mathrm{C}, 1 \mathrm{~min}$ at $60^{\circ} \mathrm{C}$ and $1 \mathrm{~min}$ at $72^{\circ} \mathrm{C}$, followed by a final extension step of $10 \mathrm{~min}$ at $72^{\circ} \mathrm{C}$. Amplified products were resolved on a $2 \%(\mathrm{w} / \mathrm{v})$ agarose/TAE (40 mM Tris-acetate, pH 7.2, 1 mM EDTA) gel containing $1.0 \mathrm{mg} / \mathrm{ml}$ ethidium bromide, and visualised under UV irradiation.

PCR products were purified using the Freeze ' $n$ Squeeze DNA purification system (Anachem), and both DNA strands were sequenced using the primers used in the initial amplification and the ABI PRISM ${ }^{\mathrm{TM}}$ dye terminator cycle sequencing system (Applied Biosystems). Sequencing was analysed using Sequencher software (Gene Codes). 
Table 1. Degenerative primers used to amplify Francisella $16 \mathrm{~S}$ gene sequences. +: positive sense; -: negative sense

\begin{tabular}{|llc|}
\hline Primer & Sequence & Orientation \\
\hline Fr153ForU & GCC CAY YWG WGG GGG ATA CC & + \\
Fr1281RevU1 & GGA CTA MGA STR SCT TTM TGR GA & - \\
Fr1281RevU2 & GGA CTA MGA STR SCT TTM TGR GT & - \\
Fr153For & GCC CAT YTG WGG GGG ATA CC & + \\
Fr1281Rev1 & GGA CTA AGA GTR GCT TTM TGA GA & - \\
Fr1281Rev2 & GGA CTA AGA GTR GCT TTM TGA GT & - \\
\hline
\end{tabular}

\section{RESULTS}

At the initial farm visit, affected fish were lethargic and hanging close to the surface. Clinical signs included flashing, fungal patches, exophthalmia, pale gills and some petechial haemorrhaging on and around the pectoral fins. Internally the fish had empty intestines and very large gall bladders. Seven of 10 fish had enlarged granular spleens (Fig. 1) and a small minority had enlarged kidneys.

Examination of H\&E stained sections revealed the presence of multiple granulomatous lesions reminiscent of those associated with mycobacteriosis in the liver, kidney, spleen and most major organs (Fig. 2). In the cases where whole fish were sectioned, lesions were present in most tissues, including the eye. No parasites and other pathologies were identified. Staining with Ziehl Neelson did not demonstrate acid fast bacteria associated with these lesions. In some
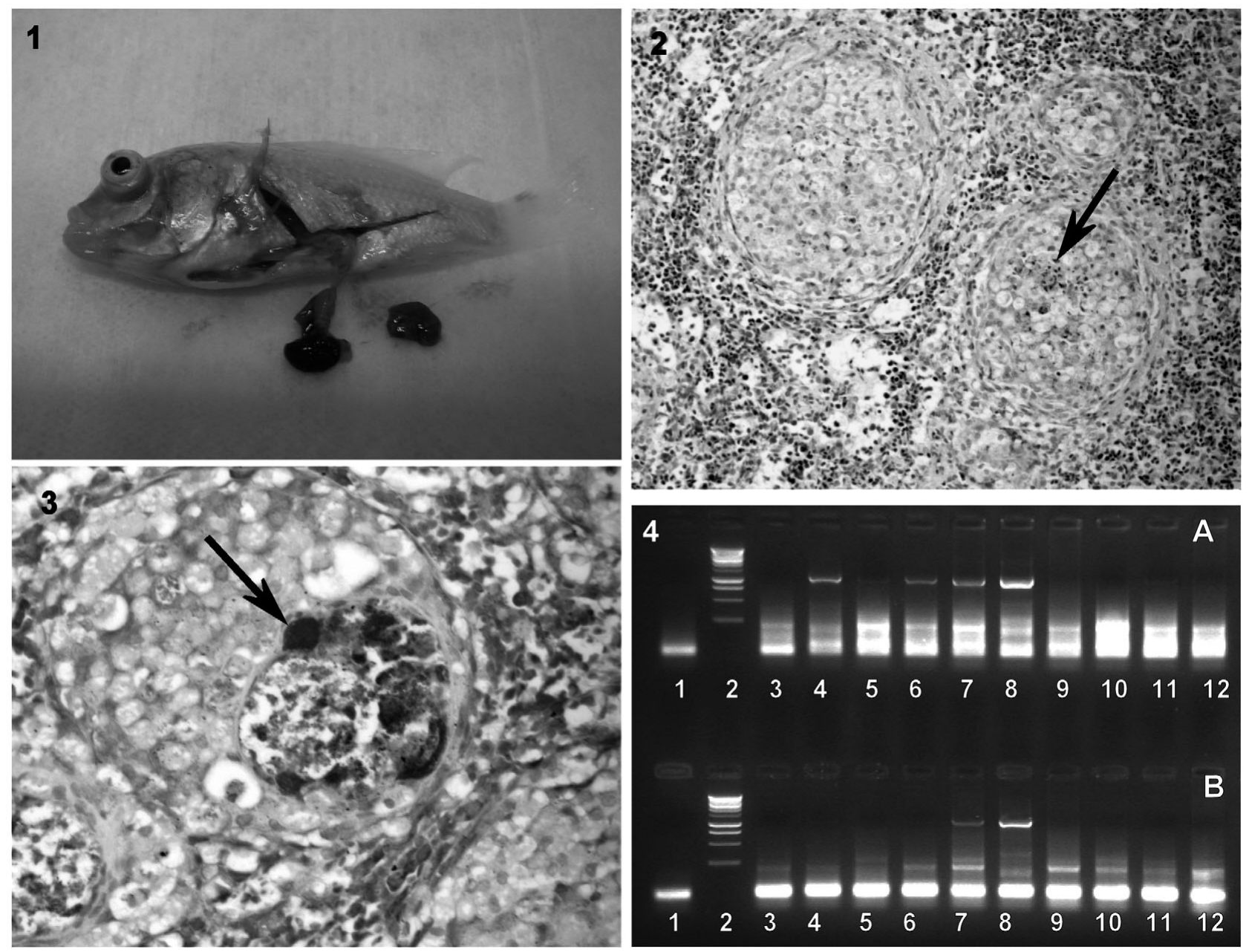

Figs. 1 to 4. Oreochromis niloticus. Fig. 1. Nile tilapia fry with grossly enlarged spleen and exophthalmia. Fig. 2. Multiple splenic granuloma in O. niloticus. The lesions are of varying size and may contain necrotic material (arrow). H\& $\bar{E}$ staining, $200 \times$. Fig. 3. High power view of a granuloma in $O$. niloticus tissue showing the presence of necrotic material associated with the presence of Francisella sp. bacteria (arrow). Gram stain, 400x. Fig. 4. Francisella sp. detection in O. niloticus tissues by PCR using (A) Fr153ForU, Fr1281RevU1 and Fr1281RevU2 and (B) Fr153For, Fr1281Rev1 and Fr1281Rev2 primer sets. Lanes: 1: negative control; 2: 100 bp ladder marker; 3-12: Samples 11-20 
cases, short Gram-negative rods were seen associated with granulomas (Fig. 3). These results indicated that the pathology was not associated with mycobacteriosis and allowed a presumptive positive diagnosis of Francisellosis.

Parasitology, virology and bacteriology investigations failed to determine a likely cause. The only parasite observed was Cichlidogyrus, which was found on the gills in low numbers. No cytopathic effect was observed on any of the inoculated cell lines. Mixed bacterial growth was observed on the majority of inoculated media plates, but nothing considered of significance, and no pathogens were identified.

Subsequent to the second site visit, PCR products of the expected size $(1.1 \mathrm{~kb})$ for Francisella were obtained using DNA extracted from Samples 12, 14, 15 and 16 when using the For/Rev1/Rev2 combination of primers. Products were generated using DNA extracted from Samples 15 and 16 using the ForU/RevU1/RevU2 combination (Fig. 4).

A 406 nucleotide DNA sequence was obtained for Samples 12, 15 and 16. A BLAST search of the GenBank database, using the facility at the National Centre for Biotechnology Information, showed that this sequence was a $100 \%$ internal match, with complete 16S rRNA gene sequences obtained from isolates previously recovered from tilapia in Costa Rica (accession no. EU597812) and three-line grunt from Japan (AB194068). One of these sequences was derived from DSM 21294T, the type strain of Francisella asiatica sp. nov. (Mikalsen \& Colquhoun 2009). Further culture attempts were unsuccessful, with no consistent isolation of any disease agent, including Francisella sp., on CHA or any of the other media used. The newly imported fry on site appeared to be healthy by histopathological examination.

\section{DISCUSSION}

The combination of the histopathology findings and partial 16S rRNA gene sequence results from the follow-up examination provide sufficient evidence to conclude that the causative agent for the losses of fry was likely to be Francisella asiatica. Failure of the Fr153ForU/Fr1281RevU1 and RevU2 primer combination to detect Francisella asiatica in Samples 12 and 14 was most probably due to a reduction in the sensitivity of the assay due to the greater number of mixed bases in these oligonucleotide primers when compared to the Fr153For/Fr1281Rev1 and Rev2 primer combination.

It is unclear why attempts to culture the organism were unsuccessful. Although the medium recommended by Hsieh et al. (2006) for culture of Francisella asiatica is different to the Cysteine Heart Agar Broth
(CHAB) deployed in the present study, Mikelsen \& Colquhoun (in press) reported that CHBA will also support the growth of F. asiatica as well as F. noatensis. It is possible that by the time samples were collected from the affected batches, the disease had regressed to such an extent that primary isolation was affected by overgrowth of other, faster-growing organisms. This was likely further complicated by the fact that the affected fish were small, making it difficult to collect affected organ material aseptically.

It is possible that francisellosis could be a more significant problem for fish farmers in recirculation systems compared with flow-through or static systems (C. Y. Hsieh pers. comm.). This might be due to high levels of background bacteria building up in high density systems with low water exchange or possibly due to the difficulty of disinfecting bio-filters.

However, it may be possible to control the disease by temperature manipulation. Mauel et al. (2007) reported that the disease was maintained between 21.5 and $26.3^{\circ} \mathrm{C}$, but that fish held between 26.5 and $29.2^{\circ} \mathrm{C}$ showed no mortality. They also reported an increase in mortality after transfer of fish between holding facilities and after increasing and decreasing water temperatures.

The route of introduction to the site is not clear. It is possible that an earlier stocking might have introduced the pathogen and that it persisted despite movement of batches through the system. Larger tilapia were maintained as 'cleaners' in the water below the suspended net hapas, removing uneaten feed passing through them on the way to the biofiltration units. If these fish were infected with the pathogen, they could have acted as carriers, infecting new batches of fish after introduction.

Subsequent to confirmation, the fish farm concerned carried out a voluntary disinfection of the site under the supervision of the Cefas Fish Health Inspectorate.

This outbreak has highlighted, among other things, the necessity for UK and other fish farmers to be aware that statutory health certificates only state that fish are from areas clear of certain listed notifiable diseases. Consequently, when beginning to farm new species, care needs to be taken when sourcing new suppliers to check if the stock is free of other non-notifiable pathogens likely to be a problem to the species concerned. It would be prudent to maintain excellent on site biosecurity by keeping any new batches of fish isolated from existing stocks for a period of quarantine.

In terms of risk to other wild species, in the case of Francisella in cod, gross observations have been made during routine research cruises off the coast of Britain and the pathogen has also been found in archive material by histopathological examination (S. W. Feist pers. obs.), which suggests that gadoids have long been 
exposed to Francisella. The risk to wild and other farmed fish from $F$. asiatica is less easily quantified. Within the UK, tilapia are only grown in heated contained systems with discharges to sewage or soakaways, and would therefore represent a low risk of any potential spread to the wild.

Treatment of diseases caused by intracellular bacterial pathogens using antimicrobials is often problematic. Future development of a vaccine for this organism would therefore be a desirable option. Overall, this experience reiterates the importance of implementing strict biosecurity measures when operating recirculated tilapia farms. As well as controlling ingress of pathogens through treatment of incoming water, and control of the movement of personnel and equipment between sites, particular attention should be paid to ensuring that the fish introduced into these systems are free of important diseases, such as francisellosis.

Acknowledgements. This work was supported by the UK Department for Environment, Food and Rural Affairs (Defra) under contracts FA001 and F1166.

\section{LITERATURE CITED}

Barns SM, Grow CC, Okinaka RT, Keim P, Kuske CR (2005) Detection of diverse new Francisella-like bacteria in environmental samples. Appl Environ Microbiol 71:5494-5500

Birkbeck TH, Bordevik M, Frøystad MK, Baklen Å (2007) Identification of Francisella sp. from Atlantic salmon, Salmo salar L., in Chile. J Fish Dis 30:505-507

Chen SC, Tung MC, Chen SP, Tsai JF and others (1994) Systematic granulomas caused by a rickettsia-like organism in Nile tilapia, Oreochromis niloticus (L.), from southern Taiwan. J Fish Dis 17:591-599

Hsieh CY, Tung MC, Tu C, Chang CD, Tsai SS (2006)

Editorial responsibility: David Bruno,

Aberdeen, UK
Enzootics of visceral granulomas associated with Francisella-like organism infection in tilapia (Oreochromis spp.). Aquaculture 254:129-138

- Hsieh CY, Wu ZB, Tung MC, Tsai SS (2007) PCR and in situ hybridization for the detection and localization of a new pathogen Francisella-like bacterium (FLB) in ornamental cichlids. Dis Aquat Org 75:29-36

Kamaishi T, Fukuda Y, Nishiyama H, Kawakami H, Matsuyama T, Yoshinaga T, Oseko N (2005) Identification and pathogenicity of intracellular Francisella bacterium in three-lined grunt Parapristipoma trilineatum. Fish Pathol 40:67-71

Little DC, Murray FJ, Azim E, Leschen W, Boyd K, Watterson A, Young A (2008) Options for producing a warm water fish in the UK: limits to 'Green Growth'? Trends Food Sci Technol 19:255-264

Mauel MJ, Soto E, Moralis JA, Hawke J (2007) A piscirickettsiosis-like syndrome in cultured Nile tilapia in Latin America with Francisella spp. as the pathogenic agent. J Aquat Anim Health 19:27-34

Mikalsen J, Colquhoun DJ (in press) Francisella asiatica sp. nov. isolated from farmed tilapia (Oreochromis sp.) and elevation of Francisella philomiragia subsp. noatunensis to species rank as Francisella noatunensis comb. nov., sp. nov. Int J Syst Evol Microbiol doi:10.1099/ijs.0.002139-0

Mikalsen J, Olsen AB, Tengs T, Colquhoun DJ (2007) Francisella philomiragia subsp. noatunensis subsp. nov., isolated from farmed Atlantic cod (Gadus morhua L.). Int J Syst Evol Microbiol 57:1960-1965

> Ottem KF, Nylund A, Karlsbakk E, Friis-Møller A, Krøssoy B, Knappskog D (2007) New species in the genus Francisella (Gammaproteobacteria; Francisellaceae); Francisella piscicida sp. nov. isolated from cod (Gadus morhua). Arch Microbiol 188:547-550

Ottem KF, Nylund A, Karlsbakk E, Friis-Møller A, Kamaishi T (2009) Elevation of Francisella philomiragia subsp. noatunensis Mikalsen et al. (2007) to Francisella noatunensis comb. nov. [syn. Francisella piscicida Ottem et al. (2008) syn. nov.] and characterization of Francisella noatunensis subsp. orientalis subsp. nov., two important fish pathogens. J Appl Microbiol 106:1231-1243

Submitted: May 22, 2009; Accepted: June 25, 2010 Proofs received from author(s): July 26, 2010 